Proceedings

\title{
Water Absorption and Effect of Water Content on Viscosity and Electrical Conductivity of Two Diethylmethylammonium Ionic Liquids ${ }^{+}$
}

\author{
María Villanueva, Carlos Fernández-Leira, Juan José Parajó *, Lois Fernández-Míguez \\ and Josefa Salgado \\ NaFoMat Group, Applied Physic and Particle Physics Departments, University of Santiago de Compostela, \\ Campus Vida, 15782 Santiago, Spain; Maria.villanueva@usc.es (M.V.); carlos.fernandez.leira@rai.usc.es \\ (C.F.-L.); lois.fernandez.miguez@raoi.usc.es (L.F.-M.); j.salgado.carballo@usc.es (J.S.) \\ * Correspondence: juanjose.parajo@usc.es \\ † Presented at the 22nd International Electronic Conference on Synthetic Organic Chemistry, 15 November- \\ 15 December 2018; Available online: https://sciforum.net/conference/ecsoc-22.
}

Published: 14 November 2018

\begin{abstract}
The effect of environmental water on certain properties of ionic liquids (ILs) can be decisive when considering a possible industrial application. The effect of environmental water absorption on electrical conductivity (using a conductimeter Crison Basic 30) and viscosity (using a rheometer AR2000 TA Instruments) on two diethylmethylammonium ionic liquids was analyzed. The studied compounds were based on a cation (diethylmethylammonium) and two anions (methanesulfonate and trifluoromethanesulfonate). In both ionic liquids the water absorption corresponded to a Fickian behavior, agreeing with previous literature data on other ILs, being methanesulfonate much more hygroscopic than trifluoromethanesulfonate ( $28 \%$ and $6 \%$ in weight for [EEMAm] $\left[\mathrm{MeSO}_{3}\right]$ and [EEMAm][OTf], respectively). As expected, water considerably increased the ionic conductivity; values were duplicated in the case of [EEMAm][OTf] and quadruplicated for [EEMAm][MeSO3]. Similarly, the viscosity decreased drastically with water incorporation in the IL-showing changes of $88 \%$ and $66 \%$ for trifluoromethanesulfonate and methanesulfonate, respectively. Furthermore, in the case of diethylmethylammonium trifluoromethanesulfonate, the functional dependence of the viscosity with the molar fraction of water was studied. According to the observed behavior, the viscosity of the pure IL was estimated using the equation proposed by Seddon et al.
\end{abstract}

Keywords: viscosity; ionic conductivity; water absorption

\section{Introduction}

The environmental water absorption study of ionic liquids (ILs) has shown their physical properties can be noticeably modified, which can be a problem for specific applications. For example, it could be expected that viscosity would vary in a sensitive way according to the incorporation of environmental water, which would seriously affect its quality as a lubricant. For this and several other reasons, the water absorption of two diethylmethylammonium ionic liquids was analyzed. Water absorption was studied with a gravimetric method until the saturation level was reached. Furthermore, the effect of the saturating water on the IL liquid range was analyzed, as well as the variation in the viscosity according to water content. 


\section{Materials and Methods}

\subsection{Chemicals}

The main characteristics of the two selected ionic liquids (ILs), both supplied by IoLiTec, are indicated in Table 1.

Table 1. Chemical structure, identification number, molecular mass and purity of the two selected ILs.

\begin{tabular}{cccccc}
\hline \multirow{2}{*}{ Name } & Abbreviation & Chemical Structure & $\begin{array}{c}\text { Molecular } \\
\text { Mass }\end{array}$ & $\begin{array}{c}\text { Mass Fraction } \\
\text { Purity }\end{array}$ \\
\cline { 2 - 2 } $\begin{array}{c}\text { Diethylmethylammonium } \\
\text { trifluoromethanesulfonate }\end{array}$ & $\begin{array}{c}\text { CAS Number } \\
945715-39-9\end{array}$ & & 237.24 & $>0.98$ \\
\hline $\begin{array}{c}\text { Diethylmethylammonium } \\
\text { methanesulfonate }\end{array}$ & $\begin{array}{c}\text { [EEMAm] } \\
945715-44-6\end{array}$ & & & 183.27 & $>0.98$ \\
\hline
\end{tabular}

\subsection{Experimental Section}

\subsubsection{Water Absorption Measurements}

In this study, samples of both liquids in their commercial form (with initial water content of $2.5 \%$ in the case of [EEMAm] [MeSO 3 ] and $0.3 \%$ for [EEMAm][OTf]), contained in two beakers, were exposed to the laboratory environment fora total period of 67 days. Data of their mass were regularly recorded through a precision scale. It was assumed that the totality of the observed mass variation would correspond to the absorption of water, despite the influence of other possible effects. The absorption process was produced at an ambient temperature between 18 and $20{ }^{\circ} \mathrm{C}$, and with a relative air humidity of around $50 \%$.

\subsubsection{Thermal Studies}

\section{Differential Scanning Calorimetry (DSC) Measurements}

A differential scanning calorimeter (DSC Q100 TA-Instruments) was used to determine the different state transitions of the IL during heating and cooling cycles. Liquid nitrogen was used as a coolant fluid. The employed methodology and procedure were the same as described in previous papers [1].

Measurements for melting and crystallization temperatures were determined to be the onset temperature of the corresponding peaks, whereas glass transition was determined to be the midpoint of a heat capacity change.

\section{Thermogravimetric Analysis (TGA) Measurements}

A thermogravimetric analyzer (TGA 7-Perkin Elmer) operating in dynamic modes under a dry air atmosphere was used to perform thermogravimetric analysis by following the methodology and procedure indicated in previous publications [2,3].

\subsubsection{Rheology}

The dynamic viscosity of the two ILs was measured at $15{ }^{\circ} \mathrm{C}$ under an air atmosphere using a TA Instruments AR2000 stress control, along with a Peltier cooling device that assured a constant temperature value. It has been used a cone and plate geometry with a diameter of $40 \mathrm{~mm}$, an angle of $1^{\circ}$ and a truncation of $30 \mu \mathrm{m}$. Both the sample and geometry were covered with a lid to avoid the exchange of atmospheric water with the environment. Flow curves were obtained using stressramped mode experiments with stress values ranging from 0:033 to $150 \mathrm{~Pa}$ over10 min. 


\subsubsection{Conductivity Measurements}

Electrical conductivity was measured using a conductimeter Crison Basic 30 at a temperature of $20{ }^{\circ} \mathrm{C}$. Priorto determining conductivity, calibration took place with a standard of $1430 \mu \mathrm{S} / \mathrm{cm}$. Experimental procedure was conducted following Prego et al. [4] methodology.

\section{Results and Discussion}

\subsection{Water Absorption Measurements}

Figure 1 shows the mass increases (in \%) versus the exposure time for both ionic liquids, [EEMAm][OTf] (a) and [EEMAm][MeSO 3$]$ (b).
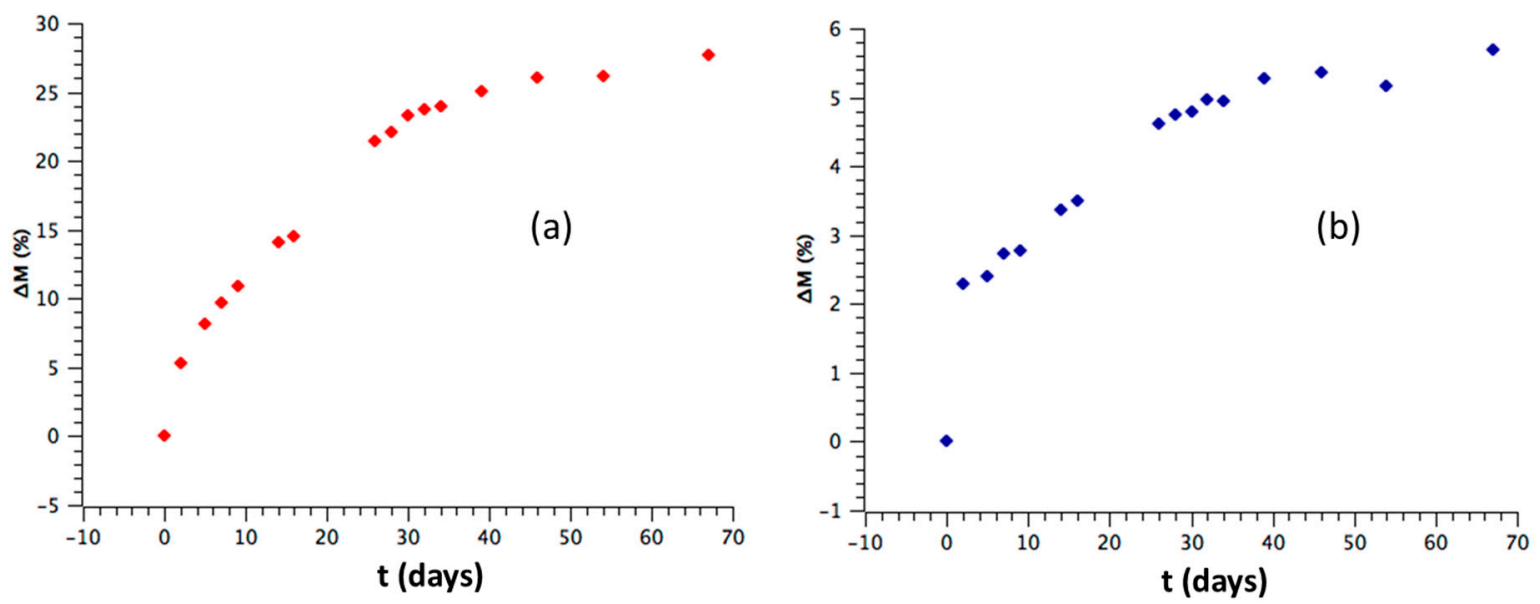

Figure 1. Water atmospheric absorption curves obtained for the ionic liquids; [EEMAm][MeSO 3$]$ (a) and [EEMAm][OTf] (b).

In both cases a Fickian behavior was observed with a linear increase at the beginning of the experiment, followed by a leveling of the water absorbed to a constant value. This tendency has previously been observed in other ILs [5]. However, saturation levels were quite different; in the case of [EEMAm][OTf] an increase of $6 \%$ in mass was reached, while almost an increase of $28 \%$ was reached for [EEMAm][MeSO 3 , which means the diethylmethylammonium IL with the methanesulfonate anion was much more hygroscopic than that with trifluoromethanesulfonate.

\subsection{Thermal Studies}

\subsubsection{DSC Measurements}

In order to study the effect of water on the liquid range of these two ILs, DSC and TGA measurements were carried out. The lower limit of this liquid window was characterized through solid-liquid transitions, while the upper limit was determined using thermo gravimetric analysis.

From DSC traces, thermal transitions were characterized through the onset of the corresponding peak in the case of melting and crystallization peaks, or as the midpoint of the heat capacity change in the case of the detection of a glass transition. Figure 2 shows the DSC curves of the ILs samples corresponding to the last cooling and heating cycles.

In both liquids it was observed that melting was not affected by water, while freezing changed with the presence of water. This was due to the fact that prior to the cooling of the IL corresponding to Figure 2, the IL was heated up to $125^{\circ} \mathrm{C}$ for $50 \mathrm{~min}$, during which almost all the absorbed water was released and only a small amount of water may have remained in the sample, thus affecting the crystallization phenomenon. Therefore, the peak associated with this last phenomenon has been moved significantly compared to the IL without water, in one case towards higher temperatures ([EEMAm] $\left.\left[\mathrm{MeSO}_{3}\right]\right)$ and in the other towards lower temperatures ([EEMAm][OTf]). In the case of 
[EEMAm] $\left[\mathrm{MeSO}_{3}\right]$ a glass transition was also detected. A possible explanation of this phenomenon could be that the high level of absorbed water may change the structure generating crystalline, along with amorphous phase being the last one responsible for the glass transition detected in the DSC experiments.
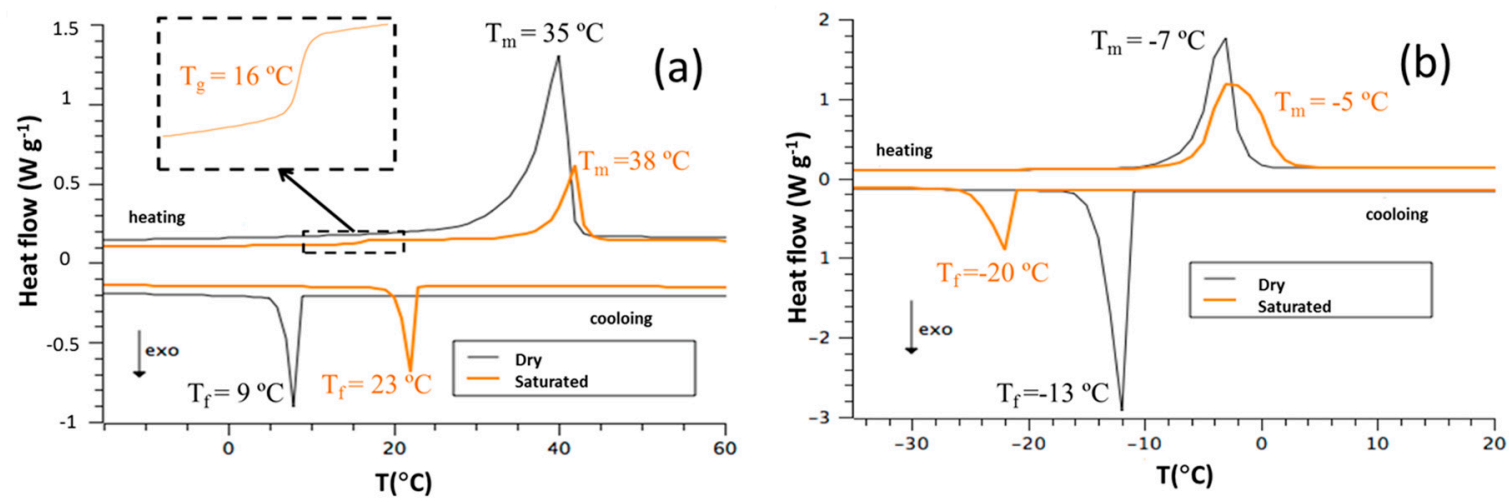

Figure 2. Differential scanning calorimetry (DSC) curves obtained for [EEMAm][MeSO 3$]$ (a) and [EEMAm][OTf] (b), with dried and saturated samples.

\subsubsection{TGA Measurements}

The TGA curves obtained for the dried and saturated ILs samples are shown in Figure 3. All experiments were performed at $10^{\circ} \mathrm{C} \cdot \mathrm{min}^{-1}$. Firstly, it was observed that saturated samples detected a loss mass step soon after the beginning of the experiment due to the presence of water. This step change in mass magnitude was very similar to the saturation level of water for dried [EEMAm][OTf]. In the case of [EEMAm][MeSO 3 ], the mass change observed in the first step of the curve do not correspond just to the content of water to. This maybe because the heating rate was much higher, allowing the complete release of water, which continued releasing at temperatures higher than 130 ${ }^{\circ} \mathrm{C}$. This was related to the smooth change in loss mass detected during the second step, which overlapped with the degradation of the ionic liquid.
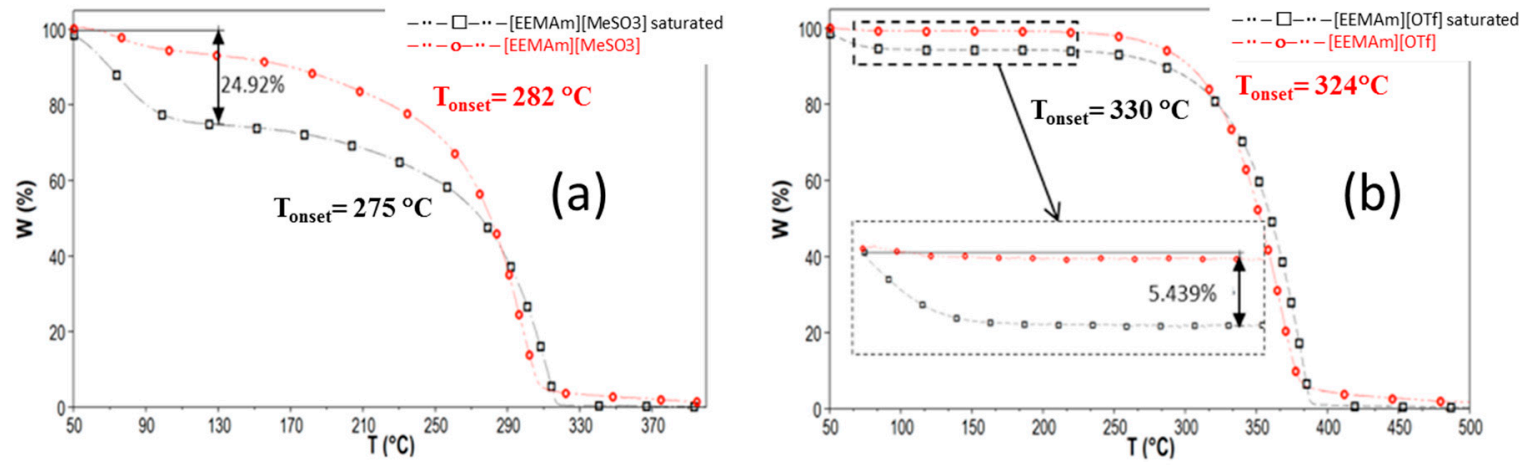

Figure 3. Thermo gravimetric analysis (TGA) curves obtained at $10^{\circ} \mathrm{C} \cdot \mathrm{min}^{-1}$ under an air atmosphere for $[E E M A m]\left[\mathrm{MeSO}_{3}\right](\mathbf{a})$ and $[\mathrm{EEMAm}][\mathrm{OTf}](\mathbf{b})$, with dried and saturated samples.

Taking into account that the liquid range can be estimated as the difference between the onset melting temperature and the onset degradation temperature, it can be concluded that the presence of water has no effect on the liquid range, as observed in Table 2. 
Table 2. Onset temperatures (all in ${ }^{\circ} \mathrm{C}$ ) associated with the melting transition ( $\left.t_{\mathrm{m}}\right)$ (DSC) and to the thermal stability $\left(t_{\mathrm{d}}\right)$ (TGA) for the two selected ILs.

\begin{tabular}{ccccccc}
\hline & \multicolumn{3}{c}{ Dry } & \multicolumn{3}{c}{ Saturated } \\
\hline Name & $\boldsymbol{t}_{\mathrm{m}}$ & $\boldsymbol{t}_{\mathrm{d}}$ & Liquid Range & $\boldsymbol{t}_{\mathrm{m}}$ & $\boldsymbol{t}_{\mathrm{d}}$ & Liquid Range \\
\hline [EEMAm] [MeSO 3$]$ & 35 & 282 & 247 & 38 & 275 & 237 \\
[EEMAm][OTf] & -7 & 324 & 331 & -5 & 330 & 335 \\
\hline \multicolumn{5}{c}{$\mathrm{U}\left(t_{\mathrm{m}}\right)=1^{\circ} \mathrm{C}, \mathrm{U}\left(t_{\mathrm{d}}\right)=5^{\circ} \mathrm{C}}$.
\end{tabular}

\subsection{Rheology}

From the linear part of the flow curves, the Newtonian fluid model was applied:

$$
\sigma=\eta \cdot \dot{\gamma}
$$

Dynamic viscosity values were calculated by substitution of experimental values to the above equation. Table 3 shows viscosity values corresponding to the ILs as supplied ( $\left.\eta_{\text {supp }}\right)$ and after water saturation $\left(\eta_{\text {sat }}\right)$.

Table 3. Obtained viscosity values corresponding to the two selected ILs as supplied and at the saturation level.

\begin{tabular}{cccc}
\hline & $\eta_{\text {supp }} / \mathbf{P a} \cdot \mathbf{s}$ & $\eta_{\text {sat }} / \mathbf{P a} \cdot \mathbf{s}$ & $-\Delta \boldsymbol{\eta} \mathbf{( \% )}$ \\
\hline$\left[\right.$ EEMAm] $\left[\mathrm{MeSO}_{3}\right]$ & $0.12579 \pm 0.00003$ & $0.01463 \pm 0.00001$ & 88.37 \\
\hline$[$ EEMAm][OTf] & $0.05430 \pm 0.00002$ & $0.01872 \pm 0.00003$ & 65.53 \\
\hline
\end{tabular}

In order to obtain more information about the influence of water on the rheological properties of the ILs, a study of the viscosity depending on the water molar fraction in [EEMAm][OTf] was carried out.

In Figure 4, flow curves corresponding to the IL [EEMAm][OTf] with different water contents are presented.

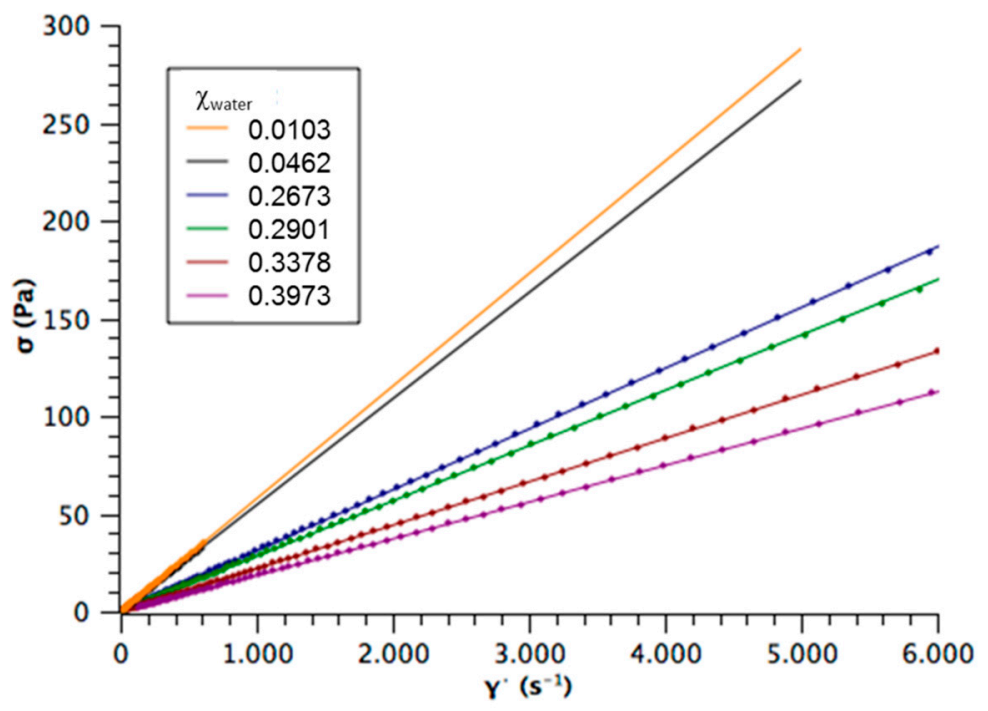

Figure 4. Newtonian region for [EEMAm][OTf] with different water contents.

As it can be seen in Table 4, Dynamic viscosity values have shown a behavior according to Newtonian fluid model. 
Table 4. Viscosities, molar fractions and decrease of viscosity calculated with respect to the degasified sample of [EEMAm][OTf] at $15^{\circ} \mathrm{C}$.

\begin{tabular}{cccc}
\hline Time (Days) & $\chi_{\text {water }}$ & $\eta$ (Pa·s) & $\Delta \eta(\%)$ \\
\hline $0\left(^{*}\right)$ & $0.01033 \pm 0.00004$ & $0.05753 \pm 0.00001$ & - \\
0 & $0.04615 \pm 0.00004$ & $0.05430 \pm 0.00002$ & $5.5993 \pm 0.0003$ \\
3 & $0.26726 \pm 0.00003$ & $0.03110 \pm 0.00001$ & $45.9331 \pm 0.0002$ \\
5 & $0.29008 \pm 0.00003$ & $0.02819 \pm 0.00001$ & $50.9883 \pm 0.0002$ \\
13 & $0.33780 \pm 0.00003$ & $0.02217 \pm 0.00004$ & $61.4568 \pm 0.0007$ \\
26 & $0.39734 \pm 0.00002$ & $0.01872 \pm 0.00003$ & $67.4628 \pm 0.0006$ \\
\hline
\end{tabular}

$\left(^{*}\right)$ degasified sample.

As expected, a noticeable decrease in viscosity values was observed as the water content increased. Following the proposition of Seddon et al. [6], a plot of $\ln \eta$ versus the molar fraction is presented in Figure 5. These values were substituted on the following equation:

$$
\eta=\eta_{s} \exp \left[-\frac{\chi_{w a t e r}}{a}\right]
$$

where $\eta_{s}$ is the viscosity of the pure IL.

Figure 5 demonstrates the good correlation of the experimental data with the above equation. The obtained value for the viscosity for the pure IL was $0.0617 \pm 0.00390 \mathrm{~Pa} \cdot \mathrm{s}$.

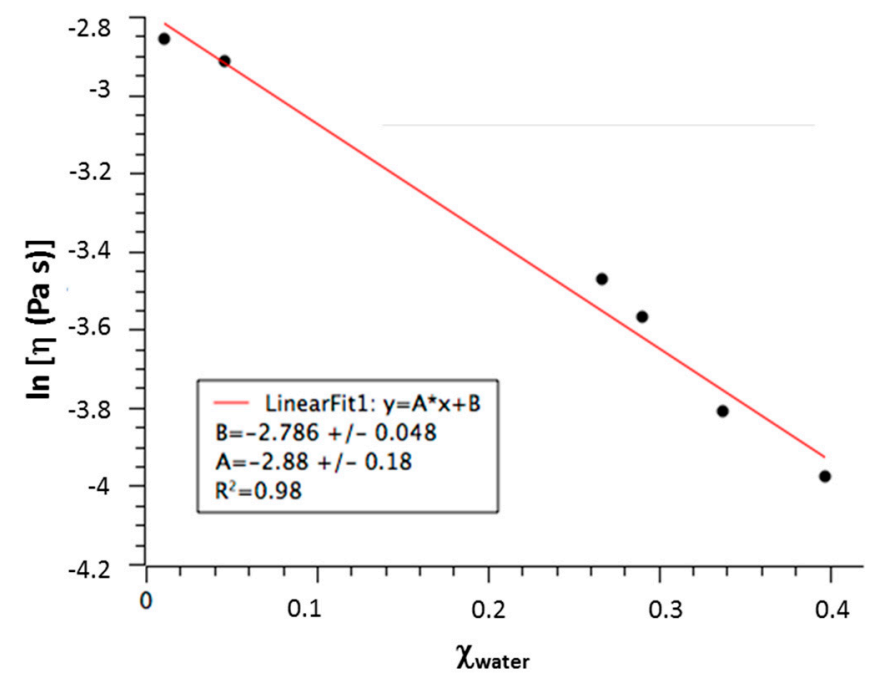

Figure 5. Experimental values substituted on the equation proposed by Seddon et al. [6].

\subsection{Electrical Conductivity}

Finally, the electrical conductivity of the initial samples (as supplied) and the saturated samples was measured with a Crison Basic 30 conductimeter. The values obtained at $20{ }^{\circ} \mathrm{C}$ and the increase in conductivity (in \%) are presented in Table 5 . As expected, an increase in conductivity was detected on the saturated samples with regard to non-saturated ones.

Table 5. Conductivity values for the two selected ionic liquids.

\begin{tabular}{cccc}
\hline$\sigma\left(\mathbf{m S} \cdot \mathbf{c m}^{-1}\right)^{*}$ & As Supplied & Saturated & $\Delta \sigma(\%)$ \\
\hline$\left[\right.$ EEMAm] $\left[\mathrm{MeSO}_{3}\right]$ & 4.64 & 18.00 & 287.9 \\
{$[$ EEMAm] } & 7.30 & 13.02 & 78.3 \\
\hline
\end{tabular}

* All $\sigma$ measurements were takenwith a resolution of $1 \%$. 


\section{Conclusions}

This study investigated the effect of water on different properties of two ionic liquids, namely [EEMAm] $\left[\mathrm{MeSO}_{3}\right]$ and [EEMAm][OTf], to achieve the following main conclusions:

- $\quad$ No noticeable effects were observed on the liquid range of both ILs. However, some change in the morphology of [EEMAm] $\left[\mathrm{MeSO}_{3}\right]$ could be assumed because of the detection of a glass transition by DSC, particularly the appearance of micro amorphous phases inside the crystalline phase.

- A decrease in viscosity was detected with water content. An estimation of the pure [EEMAm][OTf] ionic liquid was carried out using the equation proposed by Seddon et al.

- The ionic conductivity for the as-supplied and saturated samples of the two selected ionic liquids was determined, and it was observed that this physical property decreased with the presence of water at the saturated value.

Funding: This work was supported by the projects GRC ED431C 2016/001 (Xunta de Galicia, Spain) and MAT2017-89239-C2-1-P (Ministerio de Economía, Industria y Competitividad, Spain).

Acknowledgments: The authors would like to thank J.M. Sánchez for the technical support.

Conflicts of Interest: The authors declare no conflict of interest.

\section{References}

1. Villanueva, M.M.; Parajó, J.J.; Sánchez, P.B.; García, J.; Salgado, J. Liquid range temperature of ionic liquids as potential working fluids for absorption heat pumps. J. Chem. Thermodyn. 2015, 91, 127-135, doi:10.1016/j.jct.2015.07.034.

2. Parajó, J.J.; Villanueva, M.; Otero, I.; Fernández, J.; Salgado, J. Thermal stability of aprotic ionic liquids as potential lubricants. Comparison with synthetic oil bases. J. Chem. Thermodyn. 2018, 116, 185-196, doi:10.1016/j.jct.2017.09.010.

3. Salgado, J.; Parajó, J.J.; Fernández, J.; Villanueva, M. Long-term thermal stability of some 1-butyl-1methylpyrrolidinium ionic liquids. J. Chem. Thermodyn. 2014, 74, 51-57, doi:10.1016/j.jct.2014.03.030.

4. Prego, M.; Rilo, E.; Carballo, E; Franjo, C.; Jiménez, E.; Cabeza, O. Electrical conductivity data of alkanols from 273 to 333 K. J. Mol. Liq. 2003, 102, 83-91, doi:10.1016/S0167-7322(02)00049-1.

5. Cuadrado-Prado, S.; Domínguez-Pérez, M.; Rilo, E.; García-Garabal, S.; Segade, L.; Franjo, C.; Cabeza, O. Experimental measurement of the hygroscopic grade on eight imidazolium based ionic liquids. Fluid Phase Equilib. 2009, 278, 36-40, doi:10.1016/j.fluid.2008.12.008.

6. Seddon, K.R.; Stark, A.; Torres, M.J. Influence of chloride, water, and organic solvents on the physical properties of ionic liquids. Pure Appl. Chem. 2000, 72, 2275-2287.

(C) 2019 by the authors. Licensee MDPI, Basel, Switzerland. This article is an open access article distributed under the terms and conditions of the Creative Commons Attribution (CC BY) license (http://creativecommons.org/licenses/by/4.0/). 